\title{
Monocyte mRNA Phenotype and Adverse Outcomes From Pediatric Multiple Organ Dysfunction Syndrome
}

\author{
MARK W. HALL, MIKHAIL A. GAVRILIN, NINA L. KNATZ, MICHELLE D. DUNCAN, SOLEDAD A. FERNANDEZ, \\ AND MARK D. WEWERS
}

\begin{abstract}
Departments of Pediatrics [M.W.H.] and Internal Medicine [M.A.G., M.D.D., M.D.W.], The Center for Biostatistics [S.A.F.], Davis Heart and Lung Research Institute [M.W.H., M.A.G., N.L.K., M.D.D., M.D.W.], The Ohio State University College of Medicine, Columbus, Ohio 43210; Columbus Children's Research Institute [M.W.H., N.L.K.], Columbus, Ohio 43205
\end{abstract}

\begin{abstract}
Impairment of the ability to mount an inflammatory response is associated with death from adult critical illness. This phenomenon, characterized by reduced monocyte production of proinflammatory mediators such as tumor necrosis factor $\alpha$ (TNF- $\alpha$ ), is poorly understood in children. We hypothesized that differential expression of inflammation-related genes would be seen in monocytes from children with adverse outcomes from multiple organ dysfunction syndrome (MODS). Ex vivo lipopolysaccharide (LPS)induced TNF- $\alpha$ production and plasma cytokines were prospectively measured biweekly in children with dysfunction of two or more organs. Concomitantly, monocyte expression of 28 pro- and antiinflammatory genes [cytokines, Toll-like receptor (TLR)/nuclear factor $\kappa \mathrm{B}(\mathrm{NF}-\kappa \mathrm{B})$ signaling pathway members, inflammasome elements] was measured. Thirty children (22 survivors, eight nonsurvivors) were evaluated. High mRNA levels for interleukin (IL)-10, IL-1 receptor-associated kinase (IRAK-M), and the putative inflammasome inhibitor pyrin were associated with death $(p \leq 0.02)$. Plasma IL-10 levels were higher and ex vivo TNF- $\alpha$ production was lower in nonsurvivors $(p<0.05)$. Among survivors, high mRNA levels for IL-10, IRAK-M, pyrin, IRAK1, or TLR4 were associated with longer durations of pediatric intensive care unit (PICU) stay and mechanical ventilation $(p \leq 0.02)$. These data suggest that adverse outcomes from pediatric MODS are associated with an antiinflammatory monocyte mRNA phenotype. Future studies are warranted to explore mechanisms of immunodepression in pediatric critical illness. (Pediatr Res 62: 597-603, 2007)
\end{abstract}

$\mathrm{M}$ ultiple organ dysfunction syndrome (MODS) is a devastating sequela of proinflammatory insults such as sepsis, trauma, and major surgery in children and adults. Mortality rates from MODS range from $20 \%$ to $100 \%$ in children depending on the number of organ systems involved $(1,2)$. This is true despite its occurrence in a patient population in which mortality from severe sepsis in PICUs has dropped to as low as $10 \%$ in the past decade (3).

A paradigm shift is now underway in our understanding of the immunobiology of critical illness. The acute hyperinflammatory state characteristic of early sepsis was once thought to

Received January 22, 2007; accepted June 13, 2007.

Correspondence: Mark W. Hall, M.D., Columbus Children's Hospital, Critical Care Medicine, 700 Children's Drive, Columbus, OH 43205; e-mail: hallma@pediatrics.ohiostate.edu

Supplemental material available online at www.pedresearch.org.

This study was funded in part by NICHD K12 HD43372-03, NHLBI K08 HL085525-01, NHLBI 1 R01 HL076278, NHLBI R01 HL40871, and Columbus Children's Research Institute. persist through its sequelae such as MODS, but we now know that many patients experience a down-regulation of the innate immune system's inflammatory response in the aftermath of a proinflammatory insult. This state, termed immunoparalysis, is likely an initially adaptive, compensatory anti-inflammatory response, which has become exaggerated and harmful.

The monocyte has been the focus of much of the investigation into the phenomenon of immunoparalysis to date, although the overwhelming majority of data come from the setting of adult critical illness. Volk et al. (4) and others $(5,6)$ have shown that critically ill adults with persistently reduced monocyte human leukocyte antigen (HLA)-DR expression (with $<30 \%$ of circulating monocytes being HLA-DR + ) are at high risk of the development of septic complications and death. Similarly, prolonged reduction in ex vivo tumor necrosis factor $\alpha$ (TNF- $\alpha$ ) production by whole blood on exposure to endotoxin, also characteristic of monocyte deactivation, has been shown to be associated with adverse outcomes in critically ill patients (7-10). There is a growing body of evidence in adults that suggests that this deactivation may be reversible, with beneficial impact on outcomes $(11,12)$. There is a paucity of mechanistic data in the literature to provide insight into the pathways involved in this form of immunodepression in critically ill children.

In this study, we prospectively and longitudinally evaluated the associations between monocyte function, monocyte mRNA expression, and adverse outcomes from pediatric MODS. We chose to focus on three discreet sets of gene products: cytokines, members of the Toll-like receptor (TLR)/ nuclear factor $\kappa \mathrm{B}(\mathrm{NF}-\kappa \mathrm{B})$ pathway, and elements of the inflammasome complex (proteins involved in sensing internalized pathogens, activation of the NF- $\kappa \mathrm{B}$ signalosome, and processing of the immature forms of IL-1 $\beta$ and IL-18) $(13,14)$. All these proteins are important in the promotion and regulation of the inflammatory response in monocytes, and most are thought to be transcriptionally regulated. Our report demonstrates for the first time that elevations in monocyte mRNA expression for specific anti-inflammatory mediators

\footnotetext{
Abbreviations: IQR, interquartile range; IRAK, interleukin-1 receptor-associated kinase; LPS, lipopolysaccharide; MODS, multiple organ dysfunction syndrome; NF- $\boldsymbol{\kappa} \mathbf{B}$, nuclear factor $\boldsymbol{\kappa} \mathrm{B}$; OFI, organ failure index; PELOD, Pediatric Logistic Organ Dysfunction; TLR, Toll-like receptor
} 
are significantly associated with increased resource utilization and death in children with MODS. Most notably, we report an association between mRNA expression for the putative inflammasome inhibitor pyrin and adverse outcomes from critical illness, a finding that has not been previously reported in humans.

\section{METHODS}

Patients. Subjects were recruited from the Columbus Children's Hospital PICU, a 35-bed quaternary care unit in a 323-bed academic children's hospital in Columbus, $\mathrm{OH}$. Our protocol was approved by the local institutional review board and informed consent was obtained from the legal guardians of all subjects before enrollment. Patients aged $0-18$ y with indwelling vascular catheters were eligible for enrollment if they demonstrated dysfunction of two or more organs as measured by an organ failure index (OFI) (range of possible scores, 0-6) (15). Patients were excluded if they carried a preexisting limitation of care order.

Measurements. Blood samples were obtained twice weekly beginning on d 3 of MODS. Sampling was discontinued on PICU discharge or death. Sample volume at each time point was limited to $3 \mathrm{~mL}$ of blood for children younger than $1 \mathrm{y}$ of age and $5 \mathrm{~mL}$ for older children.

Cytokine determination. Plasma samples were analyzed for IL-6 and IL-10 using the Immulite automated chemiluminometer (Siemens Medical Solutions Diagnostics, Los Angeles, CA). Cytokine standards were run before each assay to ensure proper calibration. Monocyte function was measured using a commercial ex vivo stimulation assay from Milenia Biotec (Bad Nauheim, Germany). Briefly, $50 \mu \mathrm{L}$ of heparinized whole blood was added to $500 \mu \mathrm{L}$ of stimulation reagent $(500 \mathrm{pg} / \mathrm{mL}$ lipopolysaccharide (LPS)) and incubated at $37^{\circ} \mathrm{C}$ for $4 \mathrm{~h}$. The supernatant was then analyzed for TNF- $\alpha$ also using the Immulite automated chemiluminometer.

Monocyte isolation and RNA determination. We used relative quantification to evaluate the expression of 28 selected genes representing both proand anti-inflammatory cytokines, TLR/NF- $\kappa \mathrm{B}$ signaling pathway members, and elements of the inflammasome complex (Table 1). Monocytes were isolated and mRNA was quantified relative to a panel of housekeeping genes as previously described (16). Additional detail on this technique is provided in the online supplement. In brief, RNA was isolated and converted to cDNA by reverse transcriptase-polymerase chain reaction (RT-PCR). Quantitative PCR was then used to analyze the expression of genes of interest relative to the averaged expression of the housekeeping genes. The resulting relative copy number (RCN) for a given gene of interest is, therefore, standardized against constitutively expressed housekeeping genes. This allows for direct comparison of mRNA expression across individuals, time points, and groups.

Clinical data collection. Our primary outcome variables were death before PICU discharge, duration of PICU stay, and duration of invasive mechanical ventilation. Additional data collected included age, sex, diagnoses, corticosteroid use, and initial severity of illness (on d 1 of MODS) as measured by OFI, Pediatric Risk of Mortality (PRISM) III score (17), and Pediatric Logistic Organ Dysfunction (PELOD) score (18).

Data analysis. Statistical analyses were performed using Prism4 (GraphPad Software Inc., San Diego, CA) and SAS 9 (SAS Institute Inc., Cary, NC)

Table 1. Genes evaluated by quantitative PCR

\begin{tabular}{|c|c|c|c|c|c|}
\hline \multicolumn{2}{|c|}{ Cytokines } & \multicolumn{2}{|c|}{$\begin{array}{c}\text { TLR/NF- } \kappa \mathrm{B} \text { signaling } \\
\text { pathway }\end{array}$} & \multicolumn{2}{|c|}{$\begin{array}{l}\text { Inflammasome } \\
\text { elements }\end{array}$} \\
\hline $\begin{array}{l}\text { mRNA } \\
\text { product }\end{array}$ & $\begin{array}{l}\text { Coding } \\
\text { for }\end{array}$ & $\begin{array}{l}\text { mRNA } \\
\text { product }\end{array}$ & $\begin{array}{l}\text { Coding } \\
\text { for }\end{array}$ & $\begin{array}{l}\text { mRNA } \\
\text { product }\end{array}$ & $\begin{array}{l}\text { Coding } \\
\text { for }\end{array}$ \\
\hline$T N F$ & TNF- $\alpha$ & TLR4 & TLR4 & $N A L P 1$ & NALP1 \\
\hline$I L 1 B$ & IL- $1 \beta$ & $T L R 2$ & TLR2 & CIAS1 & NALP3 \\
\hline IL6 & IL-6 & $C D 14$ & CD14 & NALP6 & NALP6 \\
\hline IL8 & IL-8 & IRAKI & IRAK1 & NALP12 & NALP12 \\
\hline IL10 & IL-10* & $I R A K 2$ & IRAK2* & CARD4 & NOD1 \\
\hline IL18 & IL-18 & IRAK3 & IRAK-M* & CARD15 & NOD2 \\
\hline \multirow[t]{5}{*}{$I L 1 R N$} & IL-1ra* & NFKBIA & $\mathrm{I} \kappa \mathrm{B} \alpha^{*}$ & CARD12 & IPAF \\
\hline & & NFKBIZ & MAIL & CASP1 & Caspase 1 \\
\hline & & NFKB1 & NFкBp50 & CASP5 & Caspase 5 \\
\hline & & RELA & $\mathrm{NF} \kappa \mathrm{Bp} 65$ & PYCARD & ASC \\
\hline & & & & $M E F V$ & Pyrin* \\
\hline
\end{tabular}

* Known or suspected anti-inflammatory mediator. IRAK, interleukin-1 receptor associated kinase. software. Descriptive statistics are displayed as median with interquartile range (IQR). Genes were only included in mortality analysis if at least three nonsurvivor values were present. Simple comparisons were made using the Mann-Whitney test or the Fisher exact test. Changes in mRNA expression and cytokine levels over time were analyzed on log-transformed data by two-way analysis of variance (ANOVA). For our mRNA data, we indicate which differences in gene expression withstand a Bonferroni correction for multiple comparisons.

For survivors, a linear regression model was used to study the relationship between elevations of monocyte mRNA levels at any time and durations of PICU stay and mechanical ventilation and control for the effect of initial severity of illness. For this analysis, an elevated mRNA level was defined as one falling in the upper quartile of all survivors' values for each gene. Due to the relatively small number of observations, the variable describing the severity of illness (PELOD score) was first fitted to the model. The categorical variable describing the each mRNA level (elevated/not elevated) was then added to this univariate model individually to fit a two-variable model. For all analyses, $p<0.05$ was considered to be significant.

\section{RESULTS}

Epidemiology. From March 2003 to September 2004, 32 children with MODS met eligibility criteria, with 30 families consenting to study participation. Two patients in our cohort did not undergo mRNA analysis due to persistent leukopenia, which precluded isolation of significant numbers of monocytes throughout their PICU stays. Of the samples from the remaining subjects, some did not undergo analysis of the full 28-gene panel due to limitations in availability of monocyte cDNA. A total of 105 sampling events occurred during the course of the study, with 80 samples from 28 subjects yielding enough mRNA for testing. Study subjects' demographic and epidemiologic data are summarized in Table 2. Patients with transplantation, although represented in our cohort, accounted

Table 2. Patient demographics*

\begin{tabular}{|c|c|}
\hline No. enrolled & 30 \\
\hline Total no. of samples collected & 105 \\
\hline Age (y) & $4(1-11)$ \\
\hline Gender & 14 males, 16 females \\
\hline \multirow[t]{8}{*}{ Primary diagnoses } & 14 primary sepsis \\
\hline & 8 pneumonia with sepsis \\
\hline & 2 meningitis with sepsis \\
\hline & 2 congenital heart disease \\
\hline & 1 bacterial tracheitis with sepsis \\
\hline & 1 DKA \\
\hline & 1 ESLD \\
\hline & 1 CVA \\
\hline \multirow[t]{7}{*}{ Primary infectious agents $\dagger$} & $8 \%$ Gram-negative \\
\hline & $25 \%$ Gram-positive \\
\hline & $21 \%$ mixed Gram-positive/-negative \\
\hline & $8 \%$ fungal \\
\hline & $8 \%$ viral \\
\hline & $4 \%$ rickettsial \\
\hline & $25 \%$ culture negative sepsis \\
\hline Transplant status & 5 bone marrow transplants \\
\hline Initial OFI score & $3(2-3)$ \\
\hline Initial PRISM III score & $15(10.3-19.8)$ \\
\hline Initial PELOD score & $16(11-22)$ \\
\hline Overall mortality & $8 / 30(27 \%)$ \\
\hline PICU days & $14(7.3-20.5)$ \\
\hline Ventilator days & $8.5(4.8-15.8)$ \\
\hline
\end{tabular}

CVA, cerebrovascular accident; DKA, diabetic ketoacidosis; ESLD, endstage liver disease.

* Data are expressed as median (IQR).

$\dagger$ Percentage of subjects with suspected or proven infection as part of their primary diagnosis. 
Table 3. Characteristics of nonsurvivors and survivors*

\begin{tabular}{lccc}
\hline & $\begin{array}{c}\text { Nonsurvivors } \\
(n=8)\end{array}$ & $\begin{array}{c}\text { Survivors } \\
(n=22)\end{array}$ & $p$ \\
\hline Age (y) & $3(1-7.5)$ & $4(1-12)$ & 0.56 \\
Female gender & 13 & $68 \%$ & $\mathbf{0 . 0 1 2}$ \\
With severe sepsis/septic shock & 82 & $88 \%$ & 0.99 \\
Initial OFI score & $2(2-3)$ & $3(2-4)$ & 0.15 \\
Initial PRISM III score & $18(15-21)$ & $13(10-20)$ & 0.20 \\
Initial PELOD score & $17(11-23)$ & $16(11-22)$ & 0.96 \\
Days in PICU & $10(7-23)$ & $16(11-20)$ & 0.71 \\
Days on ventilator & $16(11-20)$ & $7(3-14)$ & 0.06 \\
Days on inotropes/vasopressors $\dagger$ & $3(1-7)$ & $7(3-11)$ & 0.29 \\
Use of dopamine at any time (\%) $\dagger$ & 88 & 82 & 0.99 \\
Use of calcineurin inhibitors at & 63 & 5 & $\mathbf{0 . 0 0 2}$ \\
$\quad$ any time (\%) & & & \\
Use of MP or dexamethasone at & 88 & 68 & $\mathbf{0 . 0 1 2}$ \\
$\quad$ any time (\%) & & & \\
Use of hydrocortisone at & & & \\
$\quad$ any time (\%) & 25 & & \\
\hline
\end{tabular}

Bold type indicates comparisons with a $p$ value $<0.05$.

MP, methylprednisolone.

* Continuous data are expressed as median (IQR).

$\dagger$ Excluding dopamine at doses $<5 \mu \mathrm{g} / \mathrm{kg} / \mathrm{min}$.

$\ddagger$ At any dose.

for $<20 \%$ of subjects. Our observed mortality rate was similar to those described in the literature for children with MODS $(1,2)$.

Characteristics of nonsurvivors and survivors are shown in Table 3. Patients who had undergone bone marrow transplantation accounted for $>50 \%$ of deaths (5/8). One survivor received tacrolimus as treatment for nephrotic syndrome but had not undergone transplantation.

We also collected mRNA from four ICU control subjects (two males, two females) ranging in age from 6 mo to $11 \mathrm{y}$. These critically ill children were admitted to the PICU with single $(n=2)$ or zero $(n=2)$ organ failure as measured by OFI. Their diagnoses included diabetic ketoacidosis, Jeune syndrome, sepsis, and congenital heart disease. Control samples were collected from a single time point on d 2 of PICU stay. Complete mRNA profiles for these patients can be viewed in Table E1 in the online supplement. Differences in monocyte mRNA expression between control subjects and MODS patients are indicated in the relevant figures and tables.

Longitudinal mRNA profiles in survivors versus nonsurvivors. To examine the time course of gene transcription in our subjects, we compared monocyte mRNA expression in the first and second weeks following the onset of MODS in survivors and nonsurvivors. The average weekly value was used for subjects who had mRNA data from more than one sampling point in a week (e.g. d 3 and 7, d 10 and 14). The only mRNA products that were different between survivors and nonsurvivors were $M E F V$ and $I L 10$. Table 4 displays gene products with a $p$ value $<0.1$. The entire panel can be viewed in Tables E2 and E3 in the online supplement. Both $M E F V$ mRNA levels and ILIO mRNA levels were higher in nonsurvivors over the first $2 \mathrm{wk}$ following the onset of MODS $(p=$ 0.001 and 0.01, respectively; two-way ANOVA, Fig. 1A). Interestingly, survivors demonstrated a down-regulation of $M E F V$ mRNA compared with controls. IL-10 mRNA was
Table 4. Longitudinal differences in monocyte mRNA expression in nonsurvivors and survivors of pediatric MODS

\begin{tabular}{clllll}
\hline & & & \multicolumn{2}{c}{ Relative copy no., median (IQR) } & \\
Wk & mRNA & Coding & & \\
product & for & Nonsurvivors & Survivors & $p$ \\
\hline \multirow{2}{*}{1} & MEFV & Pyrin* & $9.1(8.6-12.0)$ & $1.4(0.2-2.9) \dagger$ & $\mathbf{0 . 0 0 8}$ \\
& IL10 & IL-10* & $2.2(0.4-3.3)$ & $0.2(0.04-1.0)$ & $\mathbf{0 . 0 2}$ \\
& NALP1 & NALP1 & $16(7.4-120.0)$ & $3.0(1.5-9.1)$ & 0.05 \\
& CARD12 & IPAF & $16(7.6-16.0)$ & $3.9(2.2-12.0)$ & 0.09 \\
2 & MEFV & Pyrin* & $15(11.0-16.0)$ & $3.6(1.8-7.9)$ & $\mathbf{0 . 0 3}$ \\
& CIAS1 & NALP3 & $3.0(2.1-3.6)$ & $12(5.6-17.0)$ & 0.08 \\
\hline
\end{tabular}

Bold type indicates comparisons with a $p$ value $<0.05$.

Monocyte mRNA values for wk 1 and 2 following the onset of MODS are displayed. Differences in gene expression with $p<0.1$ are shown. Data from the entire panel are shown in Tables E2 and E3 in the online supplement.

* Known or suspected anti-inflammatory mediator.

$\dagger p<0.05$ vs control.
A

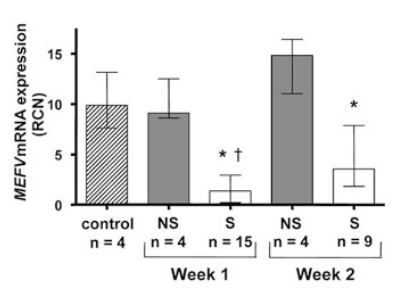

B

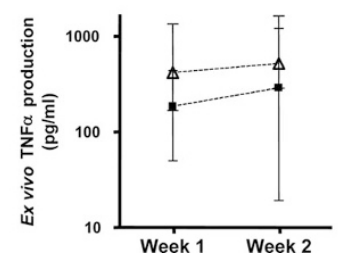

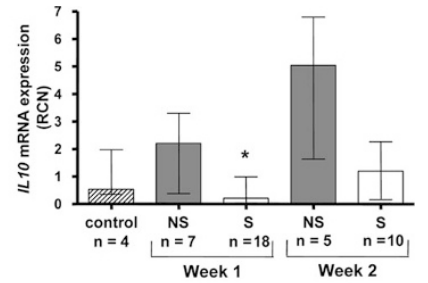

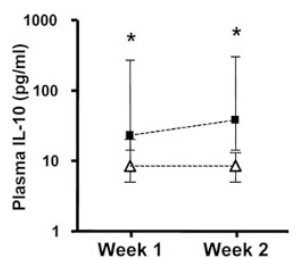

Figure 1. Longitudinal monocyte mRNA expression in survivors and nonsurvivors of pediatric MODS. (A) The two gene products that demonstrated a difference between survivors (S) and nonsurvivors (NS) with $p<0.05$ in wk 1 and/or 2 of MODS were $M E F V$ (coding for pyrin) and ILIO (coding for IL-10). $* p<0.05 v s$ nonsurvivors at same time point; $\dagger p=0.008 v s$ ICU controls with single or no organ failure; Mann-Whitney. $(B)$ Nonsurvivors $(\boldsymbol{\square}, n=8)$ demonstrated lower ex vivo TNF- $\alpha$ production and higher plasma IL-10 levels over the same time period compared with survivors $(\Delta, n=22)$ ( $p=0.017$ and 0.012 , respectively; two-way ANOVA). ${ }^{*} p<0.05 v s$ survivors by individual week by Bonferroni post-test. Data are displayed as medians with IQR throughout.

up-regulated in nonsurvivors compared with survivors. Ex vivo TNF- $\alpha$ production was lower over time in nonsurvivors compared with survivors, whereas plasma IL-10 protein levels were higher in nonsurvivors (Fig. 1B).

Early versus late mRNA expression. Monocyte mRNA from samples available from d 3 of MODS similarly showed significant differences between survivors and nonsurvivors in the expression of only two genes, MEFV and ILIO. Table 5 displays gene products with a $p$ value $<0.1$. The entire panel can be viewed in Table E4 in the online supplement.

The timeline of progression through the clinical course of MODS was predictably varied in our cohort. In fact, eight subjects (three nonsurvivors, five survivors) remained in the ICU and continued to undergo sampling $>2$ wk after the onset of MODS. These time points are difficult to compare on their own given the small sample size. To capture these values and to provide insight into differences in monocyte mRNA profiles between nonsurvivors and survivors at a time when intergroup 
Table 5. Comparison of early and late monocyte mRNA expression between nonsurvivors and survivors of pediatric MODS

\begin{tabular}{|c|c|c|c|c|c|}
\hline & mRNA product & Coding for & \multicolumn{2}{|c|}{ RCN, median (IQR) } & $p$ \\
\hline \multirow[t]{4}{*}{ D 3 of MODS } & MEFV & Pyrin* & $8.6(5.9-12.4)$ & $0.59(0.15-2.4)$ & 0.003 \\
\hline & IRAKI & IRAK1 & $3.0(2.7-4.1)$ & $1.5(1.0-2.1)$ & 0.05 \\
\hline & $T L R 4$ & TLR4 & $4.4(2.6-10.5)$ & $1.4(0.5-3.8)$ & 0.06 \\
\hline & $T L R 2$ & TLR2 & $14.1(13.5-19.1)$ & $2.1(1.3-5.9)$ & 0.06 \\
\hline \multirow{5}{*}{ Final samples } & NALP1 & NALP1 & $26.2(8.1-64.6)$ & $4.5(1.4-22.4)$ & 0.03 \\
\hline & IL10 & IL-10* & $1.2(0.4-5.4)$ & $0.2(0.03-0.87)$ & 0.02 \\
\hline & CARD12 & IPAF & $21.3(8.8-22.9)$ & $3.9(2.3-11.7)$ & 0.05 \\
\hline & NALP6 & NALP6 & $0.12(0.02-2.2)$ & $0.02(0.007-0.04)$ & 0.06 \\
\hline & $T L R 4$ & TLR4 & $7.2(0.6-8.8)$ & $1.1(0.5-3.3)$ & 0.09 \\
\hline
\end{tabular}

Bold type indicates comparisons with a $p$ value $<0.05$.

Differences in gene expression with $p<0.1$ are shown. Data from the entire panel are shown in Tables E4 and E5 in the online supplement. Final samples represent the last sample taken with 72 hours of either death (nonsurvivors) or PICU discharge (survivors).

* Known or suspected anti-inflammatory mediator.

$\dagger$ Withstands a Bonferroni correction for multiple comparisons within the 28-gene panel.

variability might be at its greatest, we compared data from the last samples taken $\leq 72 \mathrm{~h}$ before either death or PICU discharge. Table 5 also displays gene products with a $p$ value of $<0.1$ from these final samples, with the full panel displayed in Table E5 in the online supplement. There was no significant difference in time from onset of MODS to the time of final sampling between survivors (10 d; range, $3-17 ; n=19)$ and nonsurvivors ( $14 \mathrm{~d}$; range, $7-17 ; n=8 ; p=0.54$ ). Four gene products demonstrated significant differences between these groups: NALP1, IL10, IRAK3, and MEFV. Three of these four genes code for known or suspected anti-inflammatory mediators (Fig. 2A-C). Samples from the same time points revealed higher plasma IL-10 levels with reduced ex vivo TNF- $\alpha$ production in nonsurvivors compared with survivors (Fig. 2D and $E$ ).

Resource utilization among survivors. Survivors (all of whom were nontransplant recipients) with monocyte mRNA levels falling in the top quartile of all survivor samples for

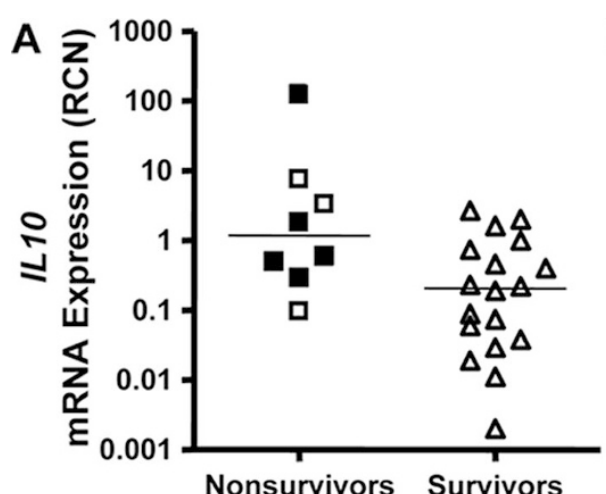

Nonsurvivors Survivors

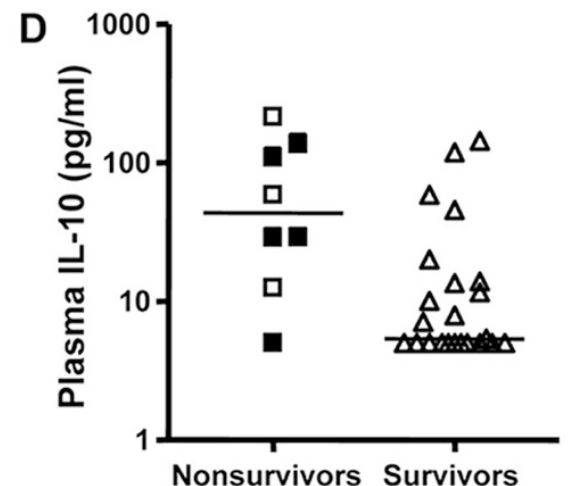

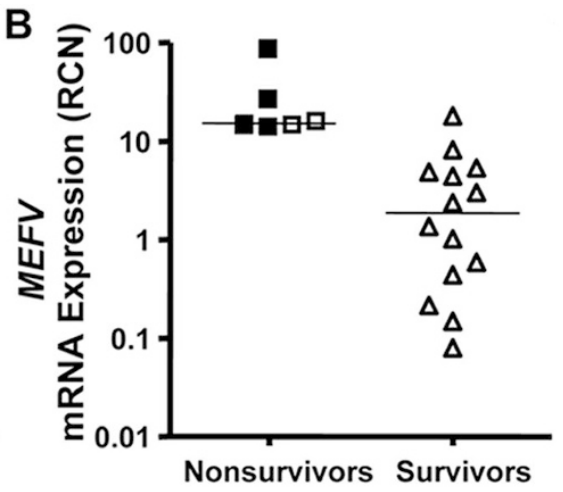

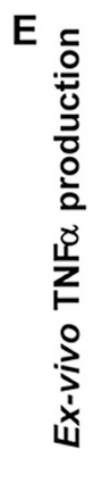

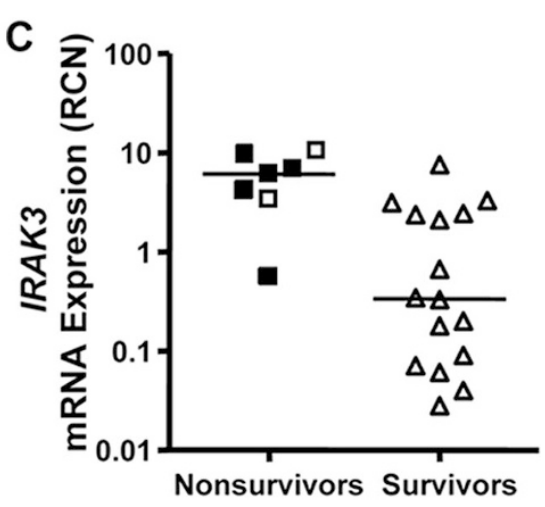

$\Delta_{\Delta}$
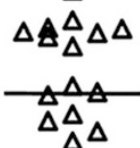

$\Delta \Delta \Delta$

$\Delta \Delta \Delta$

Figure 2. Late monocyte mRNA expression, plasma cytokines, and ex vivo TNF- $\alpha$ response in survivors $v s$ nonsurvivors with identification of transplant patients. Monocyte mRNA isolated within $72 \mathrm{~h}$ of either death (nonsurvivors) or PICU discharge (survivors) showed higher levels of message coding for IL-10 (IL10 mRNA) $(A)$, pyrin $(M E F V$ mRNA) $(B)$, and IRAK-M (IRAK3 mRNA) $(C)$ in nonsurvivors $(p=0.02,0.0006$, and 0.001, respectively). Plasma IL-10 levels were higher $(D)$, and $e x$ vivo LPS-induced TNF- $\alpha$ production was lower $(E)$, in nonsurvivor samples from the same time points $(p=0.016$ and 0.046 , respectively). Median values are indicated by the black line. Solid symbols represent transplant recipients. Open symbols represent nontransplant patients. 
Table 6. Linear regression analysis of survivor resource utilization after adjusting for initial PELOD score

\begin{tabular}{|c|c|c|c|c|c|c|c|}
\hline \multicolumn{4}{|c|}{ Duration of PICU stay } & \multicolumn{4}{|c|}{ Duration of mechanical ventilation } \\
\hline$I L 10^{*}$ & 16.1 & $6.6-25.7$ & 0.004 & $I L 10^{*}$ & 9.0 & $2.1-15.9$ & 0.02 \\
\hline $\operatorname{IRAK} 3 *$ & 16.6 & $8.4-24.8$ & 0.001 & $\operatorname{IRAK} 3^{*}$ & 10.7 & $5.2-16.2$ & 0.0015 \\
\hline IRAKI & 24.6 & $11.1-35.0$ & 0.007 & IRAKI & 13.3 & $2.7-23.8$ & 0.04 \\
\hline TLR4 & 27.2 & $20.6-33.7$ & $<0.0001$ & TLR4 & 16.4 & $10.5-22.3$ & 0.0001 \\
\hline
\end{tabular}

The slope coefficient estimates the increase in number of days of resource utilization if an elevation in mRNA level is present at any time during the course of MODS, adjusting for initial severity of illness. Elevations were defined as RCNs in the top quartile of all survivor values at any time during the course of MODS. Genes with a $p$ value of $<0.1$ are shown.

* Known or suspected anti-inflammatory mediator.

a given gene at any time were said to have elevated expression of that gene. Six genes showed an association with a longer duration of mechanical ventilation and/or longer duration of PICU stay if elevated at any time by linear regression after adjusting for initial severity of illness (Table 6).

\section{DISCUSSION}

Until recently, MODS has been viewed as a disease of hyperinflammation. In fact, elevated levels of IL-6, a marker of proinflammation, have been highly associated with adverse outcomes in adults and children with sepsis and sepsisinduced organ dysfunction (15,19-24). Over the past decade, however, increasing evidence has suggested that an exaggerated compensatory anti-inflammatory response may predominate following a proinflammatory insult and may be associated with adverse outcomes $(4,5,9,10,25)$. Our cytokine and mRNA data, taken as a whole, suggest that children with MODS who die are exhibiting an anti-inflammatory innate immune phenotype (low monocyte TNF- $\alpha$ production capability with high monocyte ILIO mRNA and high plasma IL-10 levels) both early and late in their ICU courses.

The diagnosis of severe sepsis or septic shock was common in both survivors and nonsurvivors. There was no significant difference in initial severity of illness or hydrocortisone use among groups. The high prevalence of male gender in the nonsurvivor group is intriguing. This has been shown in adults, with females demonstrating better outcomes from sepsis despite having a more robust inflammatory response to LPS than males (26). The reasons for these gender-based differences are unclear, particularly in the pediatric population.

More than half of the nonsurvivors in our cohort had undergone transplantation, accounting for high frequency of calcineurin inhibitor and methylprednisolone use in that group. Although mRNA levels were similar between nonsurvivors who had and had not undergone transplantation (Fig. 2), the potential impact of transplantation as a confounder in this subgroup is significant and difficult to control for with this sample size. We therefore analyzed resource utilization in survivors, none of whom were transplant patients. Our analysis revealed significant associations between adverse outcomes and high levels of monocyte mRNA for IL-10, interleukin-1 receptor-associated kinase (IRAK)-M, and pyrin in this group as well.
Dominance of anti-inflammatory gene products. NALP1, when measured in the terminal monocyte samples, was the only proinflammatory gene whose mRNA up-regulation positively correlated with survival in any of our analyses. This structural protein is widely expressed and is thought to be important in the assembly of both the inflammasome and proapoptotic machinery (13). The remainding gene products, which showed a positive association with mortality are at least putatively, anti-inflammatory. IL-10 is well known to induce down-regulation of the responsiveness of immune cells to endotoxin, with induction of an anti-inflammatory phenotype (27-35).

IRAK-M, encoded by the IRAK3 gene, was first described by Wesche et al. (36) in 1999 and its role as an antiinflammatory mediator more formally elucidated by Kobayashi et al. (37) in 2002. As a nonfunctional analogue of the kinase IRAK1, IRAK-M blocks signaling from the TLRs downstream to the NF- $\kappa$ B pathway. Monocyte IRAK-M levels have been shown to positively correlate with the development of monocyte hyporesponsiveness in experimental models (38-41) and in adult sepsis (38). Our findings suggest that late elevation in levels of monocyte mRNA for IRAK-M is associated with death in the setting of pediatric MODS.

Far more surprising was the striking association between mortality and $M E F V$ mRNA expression. Pyrin, encoded by the $M E F V$ gene, is an intracellular protein expressed in innate immune cells and is known to bind to both the cytoskeleton and an element of the inflammasome $(42,43)$. Although the specific functions of pyrin are not clear, it is certain that pyrin mutations are responsible for the disease familial Mediterranean fever (FMF) in which patients suffer recurrent bouts of systemic inflammation. This is thought to be the result of one of a number of loss-of-function mutations in the $M E F V$ gene $(44,45)$. Ustek et al. (46) recently demonstrated reduced levels of $M E F V$ mRNA in peripheral blood leukocytes from FMF patients who were experiencing active inflammation compared with periods of quiescence. Our patients with high levels of monocyte $M E F V$ mRNA expression demonstrated reduced ex vivo TNF- $\alpha$ production (Fig. 1B). Perhaps most intriguing is the observation that down-regulation of $M E F V$ mRNA expression was associated with survival. In contrast to FMF patients, whose hyperinflammation is associated with reduced pyrin activity, we speculate that the hypoinflammation characteristic of our children with adverse outcomes may 
be related to an overabundance of pyrin, which itself may be pathologic. Ours is the first report of expression of mRNA for pyrin being associated with death in critically ill children.

Limitations. Our study is limited by the fact that we elected to choose a small number of gene products that could be evaluated in a relatively large number of samples in a quantitative yet cost-effective way. In doing so, we were forced to restrict our focus. In addition, the volume of blood available for analysis from our pediatric subjects limited the number of monocytes available for analysis per sample. Lack of availability of data from all time points and inability to isolate sufficient RNA for measurement of all 28 genes for all patients meant that some analyses were limited in sample size. Despite this limitation, the correlation between the anti-inflammatory mRNA expression profile (IL10, IRAK3, and MEFV) and the ex vivo LPS-induced cytokine profile supports the validity of the mRNA data. A larger cohort would allow for a more rigorous regression analysis of the effects of confounders such as gender, severity of illness, corticosteroid use, and diagnosis on outcomes. This was not feasible with only eight deaths in our study. Last, our definition of elevated mRNA levels in our survivors' linear regression analysis was not based on a validated cutoff. By using the upper quartile of mRNA expression, however, we believe that we have dichotomized that group in a reasonable way to perform outcomes analysis.

\section{CONCLUSIONS}

Our observed predominance of anti-inflammatory gene expression and monocyte hyporesponsiveness in nonsurvivors of pediatric MODS is highly supportive of the notion that immunodepression is a common and concerning feature of pediatric critical illness. This study highlights the potential importance of elevated IL-10 expression as a factor in monocyte deactivation and mortality. It also adds to the relevance of IRAK-M as an in vivo modulator of the inflammatory response in critical illness. Finally, our data suggest that pyrin may play a heretofore underappreciated role in the regulation of inflammation. Inflammasome components are emerging as important in the intracellular propagation of the inflammatory response, and this study represents the first investigation of this pathway in critically ill humans. The association between levels of mRNA for pyrin, a putative inflammasome inhibitor, and mortality highlights the need for additional research in this area. The cause-and-effect relationships of these associations remain unknown and should be the subject of prospective clinical and laboratory investigation so that mechanismbased immunomodulatory protocols can be developed in an effort to improve outcomes in children with MODS.

Acknowledgments. The authors acknowledge the work of Patricia Minor, R.N., B.S.N., who participated in patient recruitment and clinical data collection.

\section{REFERENCES}

1. Tantalean JA, Leon RJ, Santos AA, Sanchez E 2003 Multiple organ dysfunction syndrome in children. Pediatr Crit Care Med 4:181-185
2. Leclerc F, Leteurtre S, Duhamel A, Grandbastien B, Proulx F, Martinot A, Gauvin F, Hubert P, Lacroix J 2005 Cumulative influence of organ dysfunctions and septic state on mortality of critically ill children. Am J Respir Crit Care Med 171:348-353

3. Watson RS, Carcillo JA, Linde-Zwirble WT, Clermont G, Lidicker J, Angus DC 2003 The epidemiology of severe sepsis in children in the United States. Am J Respir Crit Care Med 167:695-701

4. Volk HD, Reinke P, Krausch D, Zuckermann H, Asadullah K, Muller JM, Docke WD, Kox WJ 1996 Monocyte deactivation-rationale for a new therapeutic strategy in sepsis. Intensive Care Med 22:S474-S481

5. Muehlstedt SG, Lyte M, Rodriguez JL 2002 Increased IL-10 production and HLA-DR suppression in the lungs of injured patients precede the development of nosocomial pneumonia. Shock 17:443-450

6. Monneret G, Lepape A, Voirin N, Bohe J, Venet F, Debard AL, Thizy H, Bienvenu J, Gueyffier F, Vanhems P 2006 Persisting low monocyte human leukocyte antigen-DR expression predicts mortality in septic shock. Intensive Care Med 32:11751183

7. Kremer JP, Jarrar D, Steckholzer U, Ertel W 1996 Interleukin-1, -6 and tumor necrosis factor-alpha release is down-regulated in whole blood from septic patients. Acta Haematol 95:268-273

8. Majetschak M, Flach R, Kreuzfelder E, Jennissen V, Heukamp T, Neudeck F, Schmit-Neuerburg KP, Obertacke U, Schade FU 1999 The extent of traumatic damage determines a graded depression of the endotoxin responsiveness of peripheral blood mononuclear cells from patients with blunt injuries. Crit Care Med 27:313-318

9. Heagy W, Nieman K, Hansen C, Cohen M, Danielson D, West MA 2003 Lower levels of whole blood LPS-stimulated cytokine release are associated with poorer clinical outcomes in surgical ICU patients. Surg Infect (Larchmt) 4:171-180

10. Weighardt H, Heidecke CD, Emmanuilidis K, Maier S, Bartels H, Siewert JR, Holzmann B 2000 Sepsis after major visceral surgery is associated with sustained and interferon-gamma-resistant defects of monocyte cytokine production. Surgery 127:309-315

11. Docke WD, Randow F, Syrbe U, Krausch D, Asadullah K, Reinke P, Volk HD, Kox W 1997 Monocyte deactivation in septic patients: restoration by IFN-gamma treatment. Nat Med 3:678-681

12. Nierhaus A, Montag B, Timmler N, Frings DP, Gutensohn K, Jung R, Schneider CG, Pothmann W, Brassel AK, Schulte Am, Esch J 2003 Reversal of immunoparalysis by recombinant human granulocyte-macrophage colony-stimulating factor in patients with severe sepsis. Intensive Care Med 29:646-651

13. Ting JP, Davis BK 2005 CATERPILLER: a novel gene family important in immunity, cell death, and diseases. Annu Rev Immunol 23:387-414

14. Martinon F, Tschopp J 2005 NLRs join TLRs as innate sensors of pathogens. Trends Immunol 26:447-454

15. Doughty LA, Kaplan SS, Carcillo JA 1996 Inflammatory cytokine and nitric oxide responses in pediatric sepsis and organ failure. Crit Care Med 24:1137-1143

16. Gavrilin MA, Bouakl IJ, Knatz NL, Duncan MD, Hall MW, Gunn JS, Wewers MD 2006 Internalization and phagosome escape required for Francisella to induce human monocyte IL-1 $\beta$ processing and release. Proc Natl Acad Sci U S A 103:141-146

17. Pollack MM, Patel KM, Ruttimann UE 1996 PRISM III: an updated Pediatric Risk of Mortality score. Crit Care Med 24:743-752

18. Leteurtre S, Martinot A, Duhamel A, Proulx F, Grandbastien B, Cotting J, Gottesman R, Joffe A, Pfenninger J, Hubert P, Lacroix J, Leclerc F 2003 Validation of the paediatric logistic organ dysfunction (PELOD) score: prospective, observational, multicentre study. Lancet 362:192-197

19. Bell MJ, Kochanek PM, Doughty LA, Carcillo JA, Adelson PD, Clark RS, Whalen MJ, DeKosky ST 1997 Comparison of the interleukin-6 and interleukin-10 response in children after severe traumatic brain injury or septic shock. Acta Neurochir Suppl 70:96-97

20. Simmons EM, Himmelfarb J, Sezer MT, Chertow GM, Mehta RL, Paganini EP, Soroko S, Freedman S, Becker K, Spratt D, Shyr Y, Ikizler TA 2004 Plasma cytokine levels predict mortality in patients with acute renal failure. Kidney Int 65:1357-1365

21. Shorr AF, Thomas SJ, Alkins SA, Fitzpatrick TM, Ling GS 2002 D-dimer correlates with proinflammatory cytokine levels and outcomes in critically ill patients. Chest 121:1262-1268

22. Terregino CA, Lopez BL, Karras DJ, Killian AJ, Arnold GK 2000 Endogenous mediators in emergency department patients with presumed sepsis: are levels associated with progression to severe sepsis and death? Ann Emerg Med 35:26-34

23. Weeks JW, Reynolds L, Taylor D, Lewis J, Wan T, Gall SA 1997 Umbilical cord blood interleukin-6 levels and neonatal morbidity. Obstet Gynecol 90:815-818

24. Calandra T, Gerain J, Heumann D, Baumgartner JD, Glauser MP 1991 High circulating levels of interleukin-6 in patients with septic shock: evolution during sepsis, prognostic value, and interplay with other cytokines. The Swiss-Dutch J5 Immunoglobulin Study Group. Am J Med 91:23-29

25. Allen ML, Peters MJ, Goldman A, Elliott M, James I, Callard R, Klein NJ 2002 Early postoperative monocyte deactivation predicts systemic inflammation and prolonged stay in pediatric cardiac intensive care. Crit Care Med 30:1140-1145

26. van Eijk LT, Dorresteijn MJ, Smits P, van der Hoeven JG, Netea MG, Pickkers P 2007 Gender differences in the innate immune response and vascular reactivity following the administration of endotoxin to human volunteers. Crit Care Med 35:1464-1469

27. Joyce DA, Steer JH, Kloda A 1996 Dexamethasone antagonizes IL-4 and IL-10induced release of IL-1RA by monocytes but augments IL-4-, IL-10-, and TGFbeta-induced suppression of TNF-alpha release. J Interferon Cytokine Res 16:511517 
28. Clarke CJ, Hales A, Hunt A, Foxwell BM 1998 IL-10-mediated suppression of TNF-alpha production is independent of its ability to inhibit NF kappa B activity. Eur J Immunol 28:1719-1726

29. Fiorentino DF, Zlotnik A, Mosmann TR, Howard M, O'Garra A 1991 IL-10 inhibits cytokine production by activated macrophages. J Immunol 147:3815-3822

30. Bogdan C, Vodovotz Y, Nathan C 1991 Macrophage deactivation by interleukin 10. J Exp Med 174:1549-1555

31. Oswald IP, Wynn TA, Sher A, James SL 1992 Interleukin 10 inhibits macrophage microbicidal activity by blocking the endogenous production of tumor necrosis factor alpha required as a costimulatory factor for interferon gamma-induced activation. Proc Natl Acad Sci U S A 89:8676-8680

32. Oswald IP, Gazzinelli RT, Sher A, James SL 1992 IL-10 synergizes with IL-4 and transforming growth factor-beta to inhibit macrophage cytotoxic activity. J Immunol 148:3578-3582

33. Chadban SJ, Tesch GH, Foti R, Lan HY, Atkins RC, Nikolic-Paterson DJ 1998 Interleukin-10 differentially modulates MHC class II expression by mesangial cells and macrophages in vitro and in vivo. Immunology 94:72-78

34. Shin DI, Banning U, Kim YM, Verheyen J, Hannen M, Bonig H, Korholz D 1999 Interleukin 10 inhibits TNF-alpha production in human monocytes independently of interleukin 12 and interleukin 1 beta. Immunol Invest 28:165-175

35. Schottelius AJ, Mayo MW, Sartor RB, Baldwin AS Jr 1999 Interleukin-10 signaling blocks inhibitor of kappaB kinase activity and nuclear factor kappaB DNA binding. J Biol Chem 274:31868-31874

36. Wesche H, Gao X, Li X, Kirschning CJ, Stark GR, Cao Z 1999 IRAK-M is a novel member of the Pelle/interleukin-1 receptor-associated kinase (IRAK) family. J Biol Chem 274:19403-19410

37. Kobayashi K, Hernandez LD, Galan JE, Janeway CA Jr, Medzhitov R, Flavell RA 2002 IRAK-M is a negative regulator of Toll-like receptor signaling. Cell 110:191-202

38. Escoll P, del Fresno C, Garcia L, Valles G, Lendinez MJ, Arnalich F, Lopez-Collazo E 2003 Rapid up-regulation of IRAK-M expression following a second endotoxin challenge in human monocytes and in monocytes isolated from septic patients Biochem Biophys Res Commun 311:465-472

39. del Fresno C, Otero K, Gomez-Garcia L, Gonzalez-Leon MC, Soler-Ranger L, Fuentes-Prior P, Escoll P, Baos R, Caveda L, Garcia F, Arnalich F, LopezCollazo E 2005 Tumor cells deactivate human monocytes by up-regulating IL-1 receptor associated kinase-M expression via CD44 and TLR4. J Immunol 174:3032-3040

40. Nakayama K, Okugawa S, Yanagimoto S, Kitazawa T, Tsukada K, Kawada M, Kimura S, Hirai K, Takagaki Y, Ota Y 2004 Involvement of IRAK-M in peptidoglycan-induced tolerance in macrophages. J Biol Chem 279:6629-6634

41. Deng JC, Cheng G, Newstead MW, Zeng X, Kobayashi K, Flavell RA, Standiford TJ 2006 Sepsis-induced suppression of lung innate immunity is mediated by IRAK-M. J Clin Invest 116:2532-2542

42. Shoham NG, Centola M, Mansfield E, Hull KM, Wood G, Wise CA, Kastner DL 2003 Pyrin binds the PSTPIP1/CD2BP1 protein, defining familial Mediterranean fever and PAPA syndrome as disorders in the same pathway. Proc Natl Acad Sci U S A 100:13501-13506

43. Richards N, Schaner P, Diaz A, Stuckey J, Shelden E, Wadhwa A, Gumucio DL 2001 Interaction between pyrin and the apoptotic speck protein (ASC) modulates ASC-induced apoptosis. J Biol Chem 276:39320-39329

44. Schaner PE, Gumucio DL 2005 Familial Mediterranean fever in the post-genomic era: how an ancient disease is providing new insights into inflammatory pathways. Curr Drug Targets Inflamm Allergy 4:67-76

45. Chae JJ, Komarow HD, Cheng J, Wood G, Raben N, Liu PP, Kastner DL 2003 Targeted disruption of pyrin, the FMF protein, causes heightened sensitivity to endotoxin and a defect in macrophage apoptosis. Mol Cell 11:591-604

46. Ustek D, Ekmekci CG, Selcukbiricik F, Cakiris A, Oku B, Vural B, Yanar H, Taviloglu K, Ozbek U, Gul A 2007 Association between reduced levels of MEFV messenger RNA in peripheral blood leukocytes and acute inflammation. Arthritis Rheum 56:345-350 